\title{
Preliminary Study of Hospital Wastewater Treatment with a Submerged Membrane Bioreactor (SMBR): Case Study of Songklanagarind Hospital -Thailand
}

\author{
U. Preecha ${ }^{1}$, P. Sridang ${ }^{2 *} \&$ P. Wanichapichart ${ }^{3}$ \\ ${ }^{1}$ Faculty of Environmental Management, Prince of Songkla University (PSU), Songkhla 90112,Thailand \\ ${ }^{2}$ Department of Civil Engineering, Faculty of Engineering, Membrane Science and Technology Research Center \\ (MSTRC), Prince of Songkla University (PSU), Songkhla 90112, Thailand \\ ${ }^{3}$ Department of Physics, Membrane Science and Technology Research Center (MSTRC), Prince of Songkla \\ a University (PSU), Songkhla 90112,Thailand
}

\begin{abstract}
The objective of this research was to study hospital wastewater treatment using a submerged membrane bioreactor (SMBR). The lab scale unit of SMBR with a working volume of 20 liters was operated at a hydraulic retention time of 0.416 day and 0.208 day at $\mathrm{F} / \mathrm{M}$ ratio of 0.18 day $^{-1}$ and, $0.29 \mathrm{day}^{-1}$. The operating conditions were set up to provide good biological treatment without sludge extraction, and two different permeate flux values were studied. The performance of membrane was studied by monitoring the variation of transmenbrane pressure (TMP) during filtration runs. The efficiency of MBR was investigated according to the daily measurements of $\mathrm{pH}$, dissolved oxygen and temperature. The COD, BOD $5, \mathrm{NH}_{4}{ }^{+} \mathrm{N}, \mathrm{TKN}$, color, turbidity, SS and Escherichia coli (E.coli) in influent and effluent were analyzed. Membrane fouling intensity occurred slowly when the system operated with flux at $10 \mathrm{~L} / \mathrm{h} / \mathrm{m}^{2}$ and $20 \mathrm{~L} / \mathrm{h} / \mathrm{m}^{2}$, which induced high TMP at the initial period of filtration. The fouling rate was at about $0.3022 \mathrm{mbar} /$ day for the permeation of flux at $10 \mathrm{~L} / \mathrm{h} / \mathrm{m}^{2}$. The fouling rate still remained at $0.2774 \mathrm{mbar} /$ day for $20 \mathrm{~L} / \mathrm{h} / \mathrm{m}^{2}$. The results showed the great effect of membrane use for total biomass retention and the removal rate of COD, BOD $_{5}$ and E.coli were over $90 \%$. The characteristics of sludge in SMBR showed healthy floc formations with good settling. Although the ratio of MLVSS/MLSS was lower than the normal range (about 0.2 ), it was found that the average values of $\mathrm{COD}$ and $\mathrm{NH}_{4}{ }^{+}-\mathrm{N}$ in permeate were lower than $2-80 \mathrm{mg} / \mathrm{L}$ and $0.05-6.755 \mathrm{mg} / \mathrm{L}$ while the value of turbidity was also less than 3 NTU.
\end{abstract}

Keyword: Submerged membrane bioreactor, hospital wastewater treatment, efficiency, MLSS/MLVSS

\subsection{INTRODUCTION}

The hospital is the point source of infectious wastewater because of its activities. It generates wastewater different.from domestic wastewater due to contamination by hazardous chemicals, hormones and infected microorganisms from patients [1]. In addition, most of the hospital is facing unsafe water due to contamination in

\footnotetext{
" Corresponding to: P. Sridang (email: porntip.c@psu.ac.th, porntipsridang999@gmail.com)
}

natural water resources from elsewhere. Therefore, water reuse and recycling program/concept is becoming attractive. A variety of the wastewater treatment processes have been used for treating hospital wastewater. In Thailand aerobic treatment systems are widely used and recommended such as Aerated Lagoon (AL) and Activated Sludge (AS) found in hospitals in the central or urban areas [2]. It is considered an issue if these conventional systems still have some limitation such as requiring a large space for the system, or if the AS needs attention and specialists for 
monitoring the system, and also if the quality of effluent still does not pass the Thai Standard for effluent due to the limitation of each selected process. The SMBR process has become increasingly popular in the field of wastewater treatment; it is used as a modification of AS, where the traditional secondary clarifier is replaced by a membrane unit for the separation of treated water from the mixed solution in the bioreactor [3]. SMBR technology has many advantages: high treated water quality, retention of all suspended solids and microorganisms, and absolute control of biomass and long hydraulic retention time. This system can operate in various conditions and its application has been widely accepted and recommended for the treatment of domestic and also industrial wastewaters. This system including the bioreactor system and membrane system, was integrated and developed from the AS wastewater treatment system. The SMBR system is mostly characterized by immersing the membrane modules as separation units directly in the bioreactor. The SMBR wastewater treatment received increasing attention because of its advantages such as complete solid removal from effluent, effluent disinfection, low/zero sludge, its compact size, low energy consumption and acceptable effluent for recycling purposes [4-6].

However, membrane fouling is a major problem affecting performance. The characteristics of fouling appear as follows: the membrane's surface is clogged by a deposited layer of particles (reversible fouling), and the soluble substances of macromolecules are adsorbed in membrane material. The latter induces membrane fouling in long periods of filtration as defined in irreversible fouling for example. To overcome the membrane performance the operating conditions in SMBR should be of concern. Aeration at different degrees promotes and induces the local shear stress close to membrane surface. This technique also produces the circulation of flow inside, favoring the movement of the membrane if membrane fiber is used. Moreover, the permeation of flux is recommended in the sub-critical region. Besides, the formation of biomass cake layer on the membrane surface can be observed playing a key factor in the efficiency and performance of SMBR [6-9].

The objective of this work was to study the effect of sub-critical permeation flux on the efficiency and performance of the submerged membrane bioreactor for the hospital's wastewater treatment.

\subsection{EXPERIMENTAL SET-UP AND OPERATION}

Experiments were carried out in laboratory scale SMBR units. The working volume of the reactor was about $20 \mathrm{~L}$. A detailed schematic of the pilotscale SMBR system is presented in Figure 1. The membrane module used was a hollow fiber membrane module, made from PolyethyleneHydrophilic Polymer Membrane, with a pore size of $0.22 \mathrm{~mm}$ and a filtration area of $0.2 \mathrm{~m}^{2} /$ module. The hollow fiber membrane module was directly submerged in the reactor, in which the aeration.

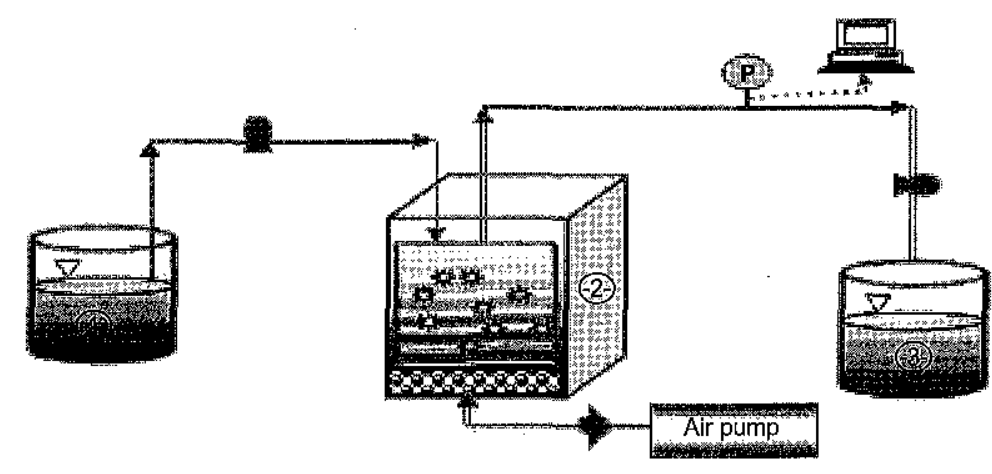

Figure 1 Schematic diagram of SMBR (1) Influent tank, (2) Bioreactor with air bubbling system and membrane module, (3) Permeate tank 
system was installed under the module providing air bubbling close to the fiber network. The air flow rate was set up at $5 \mathrm{~L} /$ minute optimizing dissolved oxygen, not less than $2 \mathrm{mg} / \mathrm{L}$, for microorganisms and membrane movement, to create a shear force close to the fiber bundle hindering membrane fouling. The solid accumulation and biomass on the membrane surface were controlled and related by a sheering stress from bubble turbulence. The pressure sensor was installed to monitor the variation in the TMP. The sub-critical condition was recommended in this study and filtered with two different permeate flux values, 10 and $20 \mathrm{~L} / \mathrm{h} / \mathrm{m}^{2}$, according to the reported subcritical flux values $[8-9,14]$. Real hospital wastewater was pumped to the bioreactor from the feed tank and passed to the SMBR unit. Effluent or permeate was extracted by a peristaltic pump at a constant flux.

The operating conditions were designed accordingly to enhance biological activity and minimize membrane fouling. The sub-critical permeation flux was investigated and captured at 10 and $20 \mathrm{~L} / \mathrm{h} / \mathrm{m}^{2}$ and operated well at the two HRT examined. Filtration was studied at room temperature and physical-chemical conditions controlled at a suitable range for biological treatment. This SMBR operated without sludge extraction excepting when the samples of sludge were taken out for mixed liquor suspended solids (MLSS), mixed liquor volatile suspended solids (MLVSS) and biomass compositions analysis. The experimental conditions are summarized in Table 1.

Table 1 Operating conditions

\begin{tabular}{lcc}
\hline \multirow{1}{*}{ Conditions } & \multicolumn{2}{c}{ Values } \\
\cline { 2 - 3 } & \multicolumn{2}{c}{$\begin{array}{c}\text { Permeate flux } \\
\left(\mathbf{L} / \mathbf{h} / \mathbf{~ m}^{\mathbf{2}}\right)\end{array}$} \\
\hline Permeation of flux & $\mathbf{1 0}$ & $\mathbf{2 0}$ \\
Hydraulic retention time (day) & 0.416 & 0.208 \\
$\mathrm{pH}$ & $6.8-8.2$ & $6.8-8.2$ \\
Temperature $\left({ }^{\circ} \mathrm{C}\right)$ & $25-30$ & $25-30$ \\
F/M ratio, day ${ }^{-1}$. & 0.18 & 0.29 \\
Air flow rate (L/min) & 5 & 5 \\
TMP limitation (bar) & 0.5 & 0.5 \\
\hline
\end{tabular}

To avoid over-fouling of the membrane, the limitation of 'TMP was controlled and the cleaning processes were performed when the TMP increased to 0.5 bars. The specific cleaning steps were different in the hydrodynamic and chemical methods: rinsing with water, backwashing with water at $10 \mathrm{~L} / \mathrm{h} / \mathrm{m}^{2}$ for 1 hour, backwashing with $1 \% \mathrm{w} / \mathrm{v}$ citric acid at flux $10 \mathrm{~L} / \mathrm{h} / \mathrm{m}^{2}$ for 1 hour and immersed in $1 \% \mathrm{w} / \mathrm{v}$ citric acid for 1 hour, backwashing with $1 \% \mathrm{w} / \mathrm{v}$ caustic at flux $10 \mathrm{~L} / \mathrm{h}$ / $\mathrm{m}^{2}$ for 1 hour and immersed in sodium hypochlorite $1 \% \mathrm{w} / \mathrm{v}$ cleaning for 1 hour. The permeability of water was measured after each cleaning step. The origin and potential of membrane fouling can be identified if the causes are present.

\subsection{CHARACTERISTICS OF STUDIED HOSPITAL WASTEWATER AND SEEDING SLUDGE}

The SMBR used real wastewater from Songklanagarind's hospital. The characteristics of the wastewater used are summarized in Table 2. The sludge was obtained from a sludge recirculation line of an AS treatment plant of a concentrated rubber industry plant in Songkhla province. The period of sludge assimilation feeding with the hospital's wastewater was done at the beginning of the sludge concentration in the reactor at about $1,500 \mathrm{mg} / \mathrm{L}$ MLSS. Real hospital wastewater was pumped to the bioreactor from the feed tank; the removal efficiency of COD was monitored until the system came to a steady state condition. When

Table 2 Wastewater characteristics of Songklanagarind Hospital

\begin{tabular}{|c|c|}
\hline Parameters & Values $($ mean/ $\pm S D)$ \\
\hline Turbidity, NTU & $84 \pm 45$ \\
\hline Color, SU & $1.07 \pm 0.34$ \\
\hline $\mathrm{SS}, \mathrm{mg} / \mathrm{L}$ & $114.78 \pm 70.6$ \\
\hline $\mathrm{COD}, \mathrm{mg} / \mathrm{L}$ & $433.4 \pm 153.55$ \\
\hline $\mathrm{SCOD}, \mathrm{mg} / \mathrm{L}$ & $143.81 \pm 50.31$ \\
\hline $\mathrm{BOD}_{5}, \mathrm{mg} / \mathrm{L}$ & $162 \pm 36.56$ \\
\hline $\mathrm{TKN}, \mathrm{mg} / \mathrm{L}$ & $37.05 \pm 11.55$ \\
\hline $\mathrm{NH}_{4}{ }^{+}-\mathrm{N}, \mathrm{mg} / \mathrm{L}$ & $30.42 \pm 5.87$ \\
\hline E.coli/MPN & $2.1 * 10^{8}-7^{*} 10^{10}$ \\
\hline
\end{tabular}


the removal efficiency was stable at about $80 \%$ with the concentration of biomass at about 2,000 $\mathrm{mg} / \mathrm{L}$, which was transferred to the SMBR and this biomass concentration was in the normal range value of criteria design for AS.

\subsection{ANALYTICAL METHODS}

The efficiency of MBR were investigated according to the daily measurements of $\mathrm{pH}$, dissolved oxygen and temperature. The COD, BOD $5, \mathrm{NH}_{4}{ }^{+}-\mathrm{N}$, $\mathrm{TKN}$, color, turbidity, SS and Escherichia coli in influent and effluent were analyzed three times a week while the biodegradable organic content in the $\mathrm{BOD}_{5}$ was done once/twice a week. The permeate and effluent were analyzed for the nitrogen compounds in terms of $\mathrm{NO}_{3}^{-}$. N. All parameters followed standard methods $[10]$. The particle size distribution, using a Laser Particle Size Analyzer (COULTER LS230), was also studied. The structure of biomass and its population in the SMBR was analyzed using an optical microscope. The sampling of sludge for its characteristic determination, once per each experimental run, may not reduce the SRT of the system significantly.

\subsection{RESULTS AND DISCUSSION}

\subsection{COD and $\mathrm{BOD}_{5}$ Removals}

The $\mathrm{BOD}_{5} / \mathrm{COD}$ ratio of influent was moderate with values between 0.23 to 0.65 . The concentration of $\mathrm{COD}$ and $\mathrm{BOD}_{5}$ was in the range of 200 to 750 $\mathrm{mg} / \mathrm{L}$ and 130 to $220 \mathrm{mg} / \mathrm{L}$ during the course of operation. The fraction of soluble COD in the influent was an average $143.81 \pm 50.31 \mathrm{mg} / \mathrm{L}$ and the SCOD/TCOD ratio was at about 0.33 implying that the influent solids rarely contributed to the TCOD of influent while the concentration of soluble COD was comparable to the $\mathrm{BOD}_{5}$ of the influent. The removal efficiencies of the organics observed in this study are summarized in Table 3.

After steady state condition of the treatment the results showed that the SMBR had a high removal rate of $\mathrm{COD}, \mathrm{BOD}_{5}$ and Turbidity. The removal rate of $\mathrm{COD}$ and $\mathrm{BOD}_{5}$ are shown in Figures 2-3. It was found that the removal efficiency of $\mathrm{COD}$ and $\mathrm{BOD}_{5}$ of MBR was between $80-98 \%$ and over $98 \%$ whatever the permeation of flux tested. The SMBR showed an increase of removal efficiency of COD with time while the constant of $\mathrm{BOD}_{5}$ removal was observed. The soluble COD fraction could be removed by the biological

Table 3 Performance summary of SMBR

\begin{tabular}{|c|c|c|c|c|c|c|}
\hline \multirow[t]{2}{*}{ Parameter $^{\mathrm{s}}$} & \multirow[t]{2}{*}{ Wastewater } & \multirow[t]{2}{*}{$\begin{array}{c}\text { Supernatant } \\
\text { of sludge in } \\
\text { reactor }\end{array}$} & \multicolumn{2}{|c|}{$\begin{array}{c}\text { SMBR } \\
\text { permeate }\end{array}$} & \multicolumn{2}{|c|}{$\begin{array}{c}\text { Removal } \\
\text { efficiency ( } \%) \\
\text { in SMBR }\end{array}$} \\
\hline & & & $\begin{array}{c}10 \\
\left.\text { (L } / \mathbf{h} / \mathrm{m}^{2}\right)\end{array}$ & $\begin{array}{c}20 \\
\left.\text { (L } / \mathbf{h} / \mathbf{m}^{2}\right)\end{array}$ & $\begin{array}{c}10 \\
\left.\text { (L } / \mathrm{h} / \mathrm{m}^{2}\right)\end{array}$ & $\begin{array}{c}20 \\
\left(\mathrm{~L} / \mathrm{h} / \mathrm{m}^{2}\right)\end{array}$ \\
\hline Turbidity, NTU & $84 \pm 45$ & - & $1.06 \pm 0.85$ & $0.86 \pm 0.23$ & 98.60 & 98.12 \\
\hline Color, SU & $1.07 \pm 0.34$ & - & $0.46 \pm 0.08$ & $0.51 \pm 0.02$ & 54.59 & 56.92 \\
\hline $\mathrm{SS}, \mathrm{mg} / \mathrm{L}$ & $114.78 \pm 70.6$ & - & - & - & - & - \\
\hline $\mathrm{COD}, \mathrm{mg} / \mathrm{L}$ & $433.4 \pm 153.55$ & - & $35.59 \pm 24.67$ & $17.33 \pm 10.93$ & 90 & 95 \\
\hline $\mathrm{SCOD}, \mathrm{mg} / \mathrm{L}$ & $143.81 \pm 50.31$ & $89.03 \pm 29.85$ & $35.59 \pm 24.67$ & $17.33 \pm 10.93$ & 90 & 95 \\
\hline $\mathrm{BOD}_{5}, \mathrm{mg} / \mathrm{L}$ & $162 \pm 36.56$ & - & $1.88 \pm 0.94$ & $1.56 \pm 1.19$ & 98.89 & 99.04 \\
\hline $\mathrm{TKN}, \mathrm{mg} / \mathrm{L}$ & $37.05 \pm 11.55$ & - & $4.62 \pm 2$ & $6.49 \pm 2.48$ & 86.34 & 79.5 \\
\hline $\mathrm{NH}_{4}{ }^{+}-\mathrm{N}_{;} \mathrm{mg} / \mathrm{L}$ & $30.42 \pm 5.87$ & . & $3.03 \pm 1.59$ & $4.47 \pm 0.41$ & 90.06 & 8.98 \\
\hline $\mathrm{NO}_{3}{ }^{-} \mathrm{N}, \mathrm{mg} / \mathrm{L}$ & N.D & - & $20.4 \pm 7.76$ & $27.3 \pm 3.98$ & - & - \\
\hline E. coli, MPN/100 ml & $2.1 * 10^{8}-7 * 10^{10}$ & - & $4 * 10^{2}-4.6 * 10^{5}$ & $4 * 10^{2}-4 * 10^{7}$ & 99 & 99 \\
\hline
\end{tabular}

${ }^{\text {a }}$ All analyses were COD performed at steady-state period

ND : non detectable (lower than detection limit value) 


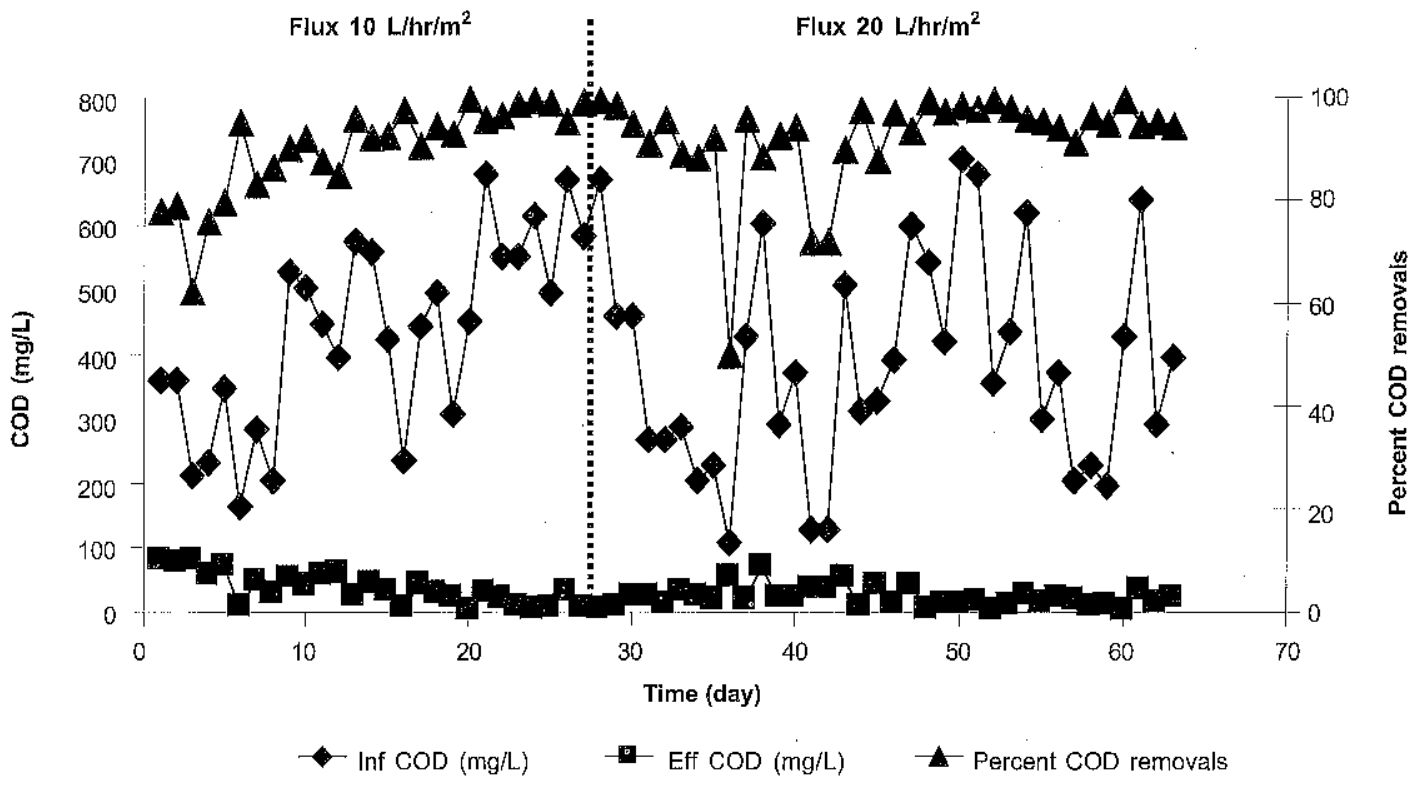

Figure 2 COD concentration and removal efficiency in the SMBR

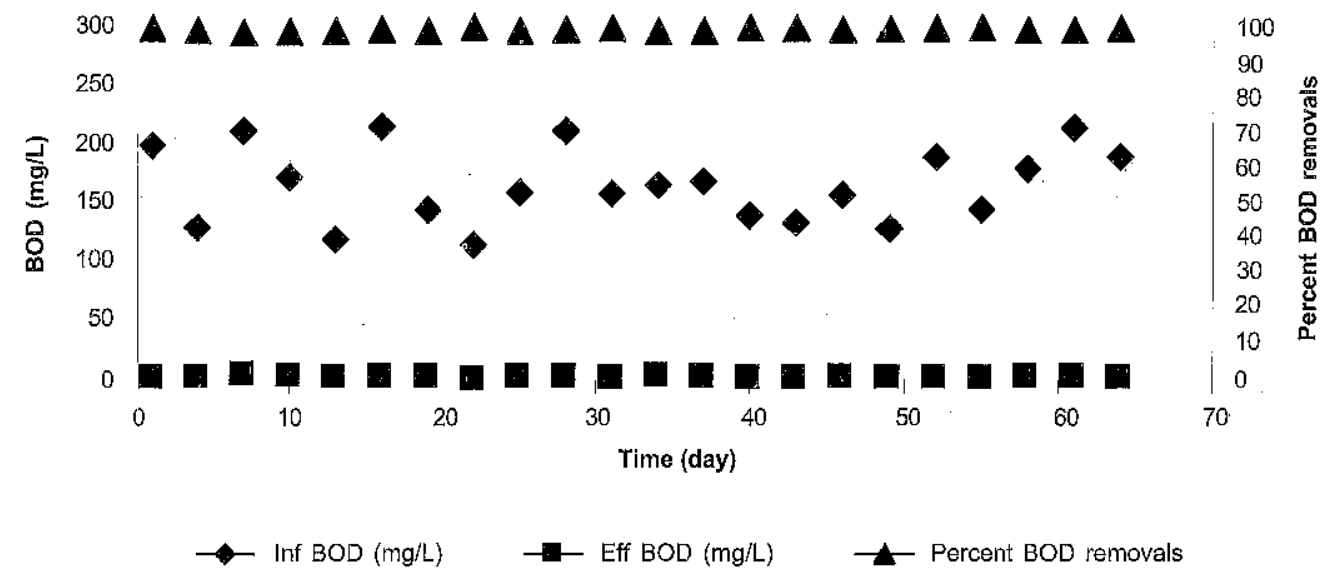

Figure $3 \mathrm{BOD}_{5}$ concentration and removal efficiency in the SMBR

reaction with efficiency between $20-75 \%$. The $\mathrm{BOD}_{5}$ concentration of effluent was less than 2.5 $\mathrm{mg} / \mathrm{L}$. The effectiveness of membrane separation can remove some fraction of soluble COD and colloids in a wide range of $20-90 \%$. However, the quality of permeate from the SMBR still remained non-biodegradable in organics in terms of COD concentration, which was not completely eliminated by biological reaction and membrane separation using the pore size studied. The residual of COD in effluent remained in the wide range of
2 to $80 \mathrm{mg} / \mathrm{L}$. However, it is supposed that the removal efficiency of soluble COD fraction will gain in the long run of operations.

Figure 4 shows the physical quality removal by this SMBR studied in terms of turbidity. The results showed that the variation of turbidity in the influent was between 21 to 205 NTU. However, the turbidity of permeate was always below 3 NTU with the removal efficiency over $98 \%$ respectively, while the effectiveness of membrane retaining E.Coli was over $99 \%$. 


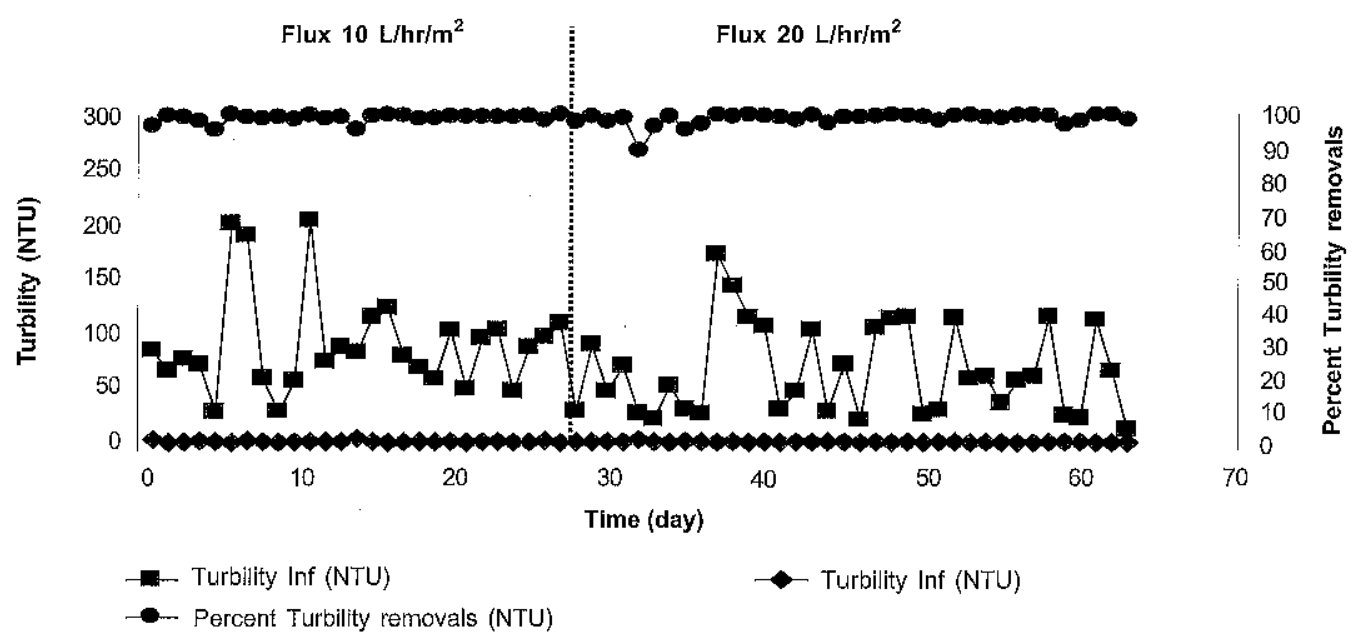

Figure 4 Turbidity removal efficiency in the SMBR

\subsection{TKN and $\mathrm{NH}_{4}{ }^{+}-\mathrm{N}$ Removals}

The amount of nitrogen compound in terms of TKN and $\mathrm{NH}_{4}^{+}-\mathrm{N}$ concentration were in the same range $\left(\mathrm{TKN}=37.05 \pm 11.55 \mathrm{mg} / \mathrm{L}\right.$ and $\mathrm{NH}_{4}^{+}-\mathrm{N}=$ $30.42 \pm 5.87 \mathrm{mg} / \mathrm{L}$ ). This indicated that most of organic nitrogen was mostly transformed to $\mathrm{NH}_{4}^{+}-\mathrm{N}$ concentration in the influent. The overall removal rate of TKN, $\mathrm{NH}_{4}^{+}-\mathrm{N}$ of MBR was observed and it was over $90 \%$ in the two conditions tested. The nitrogen compounds were mostly transformations and eliminated by the process of nitrification due to effective nitrifying bacteria growing in SMBR, which was operated in long sludge retention time. It can be seen from Figure 5 that despite the fluctuation of $\mathrm{TKN}$ and $\mathrm{NH}_{4}^{+}-\mathrm{N}$ concentration in the influent, only 0.05 to 6.755 $\mathrm{mg} / \mathrm{L}$ of $\mathrm{NH}_{4}^{+}-\mathrm{N}$ was detected in the permeate. The concentrations of $\mathrm{NO}_{3}{ }^{-} \mathrm{N}$ still remained in the range of $12.67-31.68 \mathrm{mg} / \mathrm{L}$. To eliminate and avoid the accumulation of $\mathrm{NO}_{2}{ }^{-} \mathrm{N}$ and $\mathrm{NO}_{3}{ }^{-} \mathrm{N}$ in studied SMBR, the step of denitrification will be recommended and implemented in order to process the intermittent aeration to transform $\mathrm{NO}_{3}{ }^{-} \mathrm{N}$ concentration in permeate to nitrogen gas.

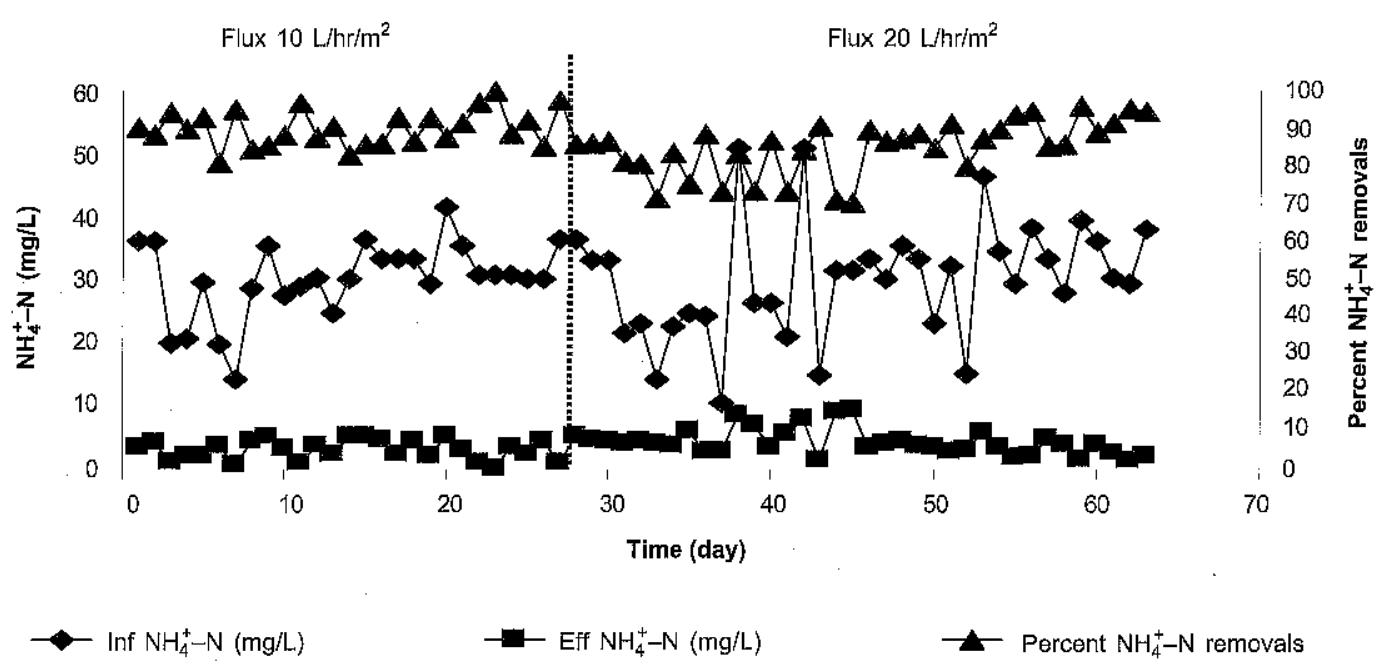

Figure 5 Concentration of $\mathrm{NH}_{4}^{+}-\mathrm{N}$ and $\mathrm{NH}_{4}^{+}-\mathrm{N}$ removal efficiency in SMBR 


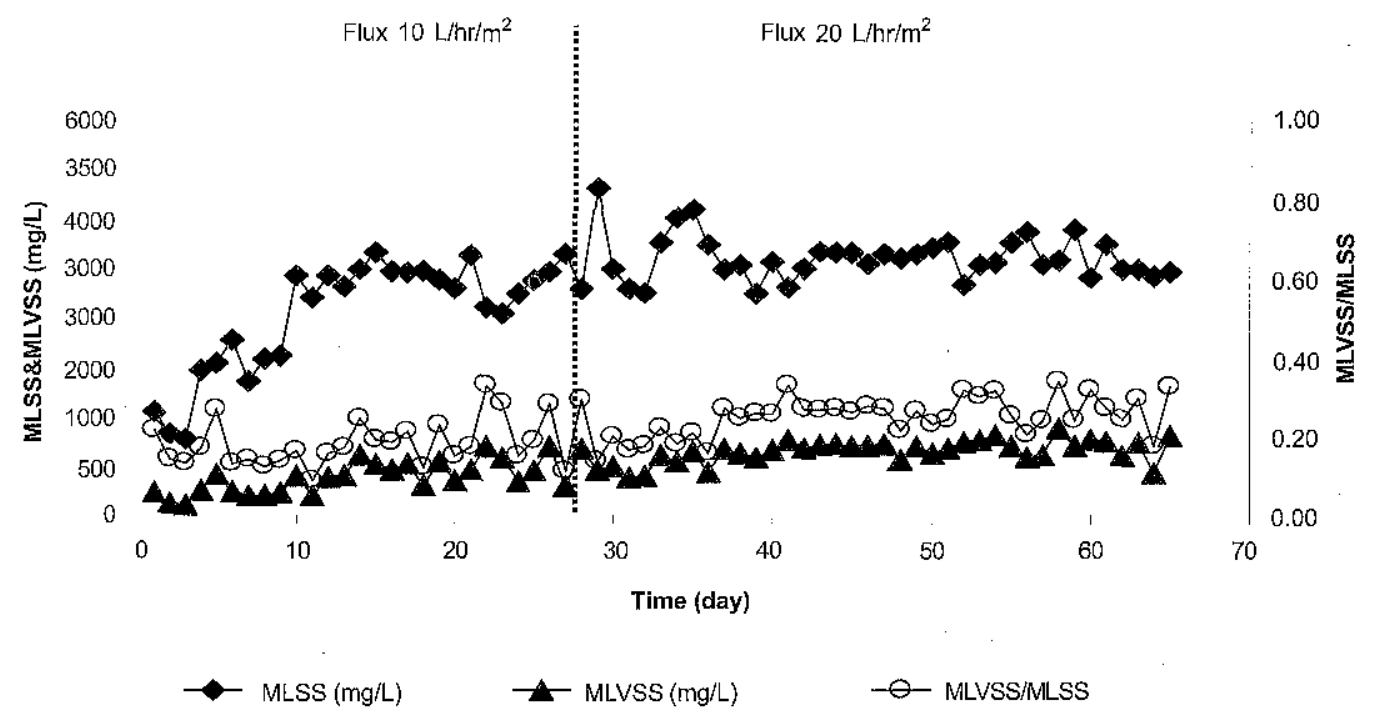

Figure 6 Sludge or biomass concentration during operation courses

\subsection{Sludge Characteristics}

The characteristics of sludge or biomass in the SMBR were analyzed and their development was also surveyed. Figure 6 shows the evolution of biomass during the course of operations. The biomass concentration (MLSS and MLVSS) was determined. It was observed that the constant or slow increase of biomass at the beginning until the day 6 of the phase in the start up period with a concentration of $1,500 \mathrm{mg} / \mathrm{L}$. After that MLSS concentration was slowly increased in a range from 1,600 to $2,500 \mathrm{mg} / \mathrm{L}$ from day 7 to day 9 . The steady state condition was reached after 12 days. The concentration of MLSS and MLVSS still increased slowly wịth time and stabilized at 2,000 $\mathrm{mg} / \mathrm{L}$ with MLVSS/MLSS $<0.3$ in SMBR. This calculated ratio was lower than the ratio values in conventional activated sludge and MBR which is known to be $0.5-0.8$ in most cases [11]. The relatively stable and low ratio of MLVSS to MLSS in this SMBR indicated that the amount of inorganic remainders constituted in the biomass [12] due to the nature of hospital wastewater contained a high composition of chemical substances [1]. However the efficiencies of treatment in SMBR were satisfied: the COD treatment efficiencies reached to $80-90 \%$ without any problem from sludge. The formation of a biomass layer on the membrane surface was also slightly observed and it plays a secondary layer as a membrane.

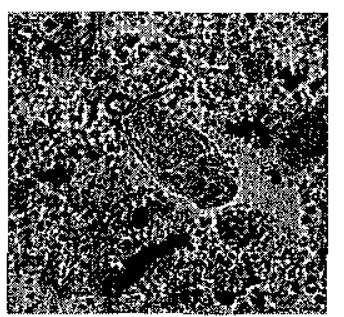

(a):Stalked ciliates $\left({ }^{*} 40\right)$

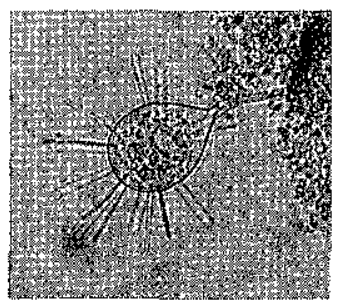

(b):Suctoria (*40)

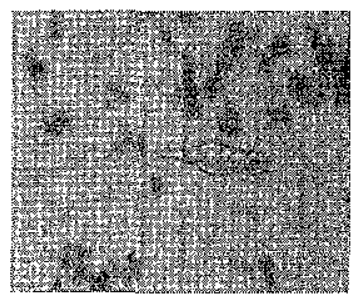

(c): Free-swimming ciliates $(* 10)$

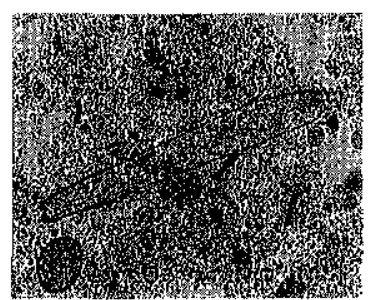

(d):Rotifer $(* 40)$

Figure 7 An example of protozoa indicating the stability of SMBR 
At a certain SRT (without sludge extraction) in this study, the excess sludge might be oxidized in the bioreactor, which will keep sludge concentrations constant during the course of operation. The SVI value was measured and its values reported to be about $103-108 \mathrm{ml} / \mathrm{g}$. This range of SVI values showed the good settling characteristic of sludge that may be expected in the SMBR, even if the system was not operating for a long enough period of time [8-9]. This result clearly showed that the sludge characteristics obtained from a short term operation of 30-35 days can represent that of a long term operation as in general AS.

The morphology of sludge and floc size determination was observed to identify the microbial community found in the SMBR (Figure 7). The mean floc size was at $54.82 \mu \mathrm{m}$. with a high variation of large and small floc sizes observed (24.01 and $82.26 \mu \mathrm{m})$. In this SMBR stalked ciliates were found higher than free swimming ones and only a few Suctoria or Rotifer. These microbials indicated and confirmed that the stability of studied SMBR was well performed whatever the permeation of flux values tested [8-9].

\subsection{Membrane Performance}

The performance of the SMBR system was investigated by monitoring the values of TMP with time. Figure 8 shows that the values of TMP increased slowly and fouling rate was an average of $0.3022 \mathrm{mbar} /$ day for the permeation of flux at $10 \mathrm{~L} / \mathrm{h} / \mathrm{m}^{2}$. When the SMBR operated at $20 \mathrm{~L} / \mathrm{h}$ / $\mathrm{m}^{2}$ the fouling rate still increased with a constant remaining rate of $0.3224 \mathrm{mbar} / \mathrm{day}$. This fouling increased slowly due to the accumulation of sludge on the membrane surface, in which some of the cake layer was removed by air scouring. However, it was still found as the biofilm or gel layer. The gel layer could function as a dynamic membrane to enhance the elimination of soluble organic matters. In addition, the adsorption of soluble organic matters in the membrane plays a key factor in irreversible fouling $[7,13]$.

The intensity of aeration considers improving and controlling biomass layer formation thus reducing reversible fouling. Moreover, it is very difficult to avoid fouling in SMBR in long runs, even if the system was set up under good operating conditions.

\subsection{CONCLUSIONS}

A Lab-scale submerged membrane bioreactor was used effectively for hospital wastewater treatment. The results showed the great effect of membrane used for total biomass retention and the removal rate of $\mathrm{COD}, \mathrm{BOD}_{5}$ and Escherichia coli were over $90 \%$. The removal efficiency of COD and $\mathrm{BOD}_{5}$ of MBR were between $80-98 \%$ and over $98 \%$ whatever the permeation of flux tested. It was found that the average values of COD and $\mathrm{NH}_{4}{ }^{+}$. $\mathrm{N}$ in permeate were lower than $2-80 \mathrm{mg} / \mathrm{L}$ and $0.05-6.755 \mathrm{mg} / \mathrm{L}$ while the value of turbidity was also less than 4 NTU. The soluble COD fraction could be removed by the biological reaction with efficiency between $20-75 \%$. The $\mathrm{BOD}_{5}$ concen-

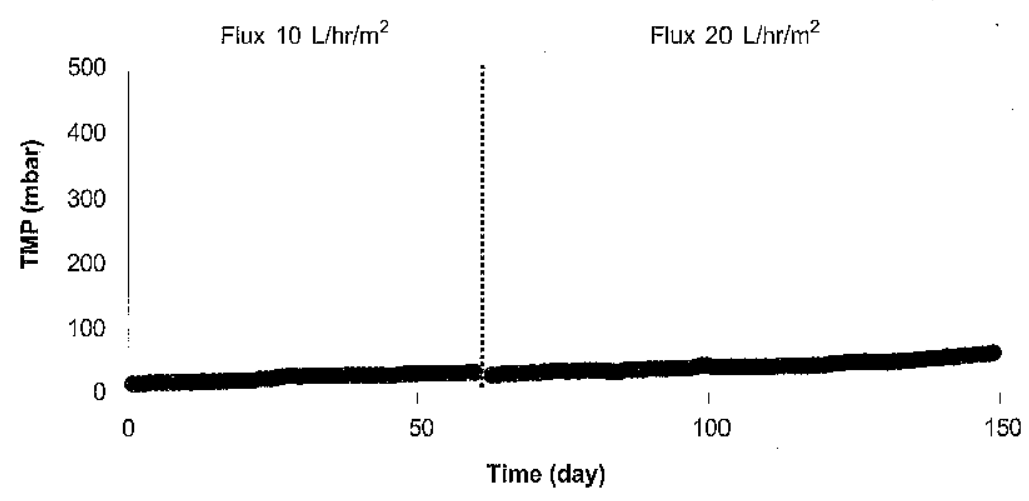

Figure 8 Transmembrane pressure evolution conclusions 
tration of effluent was less than $2.5 \mathrm{mg} / \mathrm{L}$. The effectiveness of membrane separation can remove some traction of soluble COD and colloids in a wide range of $20-90 \%$. The performance of the membrane was studied by monitoring the variation of TMP during filtration runs. The fouling rate was at about 0.324 and $0.2774 \mathrm{mbar} /$ day for the permeation of flux at 10 and $20 \mathrm{~L} / \mathrm{h} / \mathrm{m}^{2}$. The major fouling in this SMB is of an irreversible type according to the adsorption of soluble organic matters and also the biofilm layer or gel layer on the membrane surface.

\section{REFERENCES}

[1] Kajitvichyanukul, P., and N. Suntronvipart. 2006. Evaluation of Biodegradability and Oxidation Degree of Hospital Wastewater. Journal of Hazardous Materials. B138: 384-391.

[2] Wen, X., H. Ding, X. Huang, and R. Liu. 2003. Treatment of Hospital Wastewater using a Submerged Membrane Bioreactor. Process Biochemistry. 39: 1427-1431.

[3] Xing, C.-H., E. Tardiue, Y. Qian, and X-H. Wen. 2000. Ultrafiltration Membrane Bioreactor for Urban Wastewater Reclamation. Journal of Membrane Science. 117: 73-82

[4] Rautenbach, R., and K. Voßenkaul. 2001. Pressure Driven Membrane Process-the Answer to the Need of a Growing World Population for Quality Water Supply and Waste Water Disposal. Separation and Purification Technology. 22-23: 193-208.

[5] Defrance, L., and M.Y. Jaffrin. 1999. Comparison between Filtrations at Fixed Transmembrane Pressure and Fixed Permeate Flux: Application to a Membrane Bioreactor used for Wastewater Treatment. Journal of Membrane Science. 152: 203-210.

[6] Winnen, H., T. Suidan, M. Scarpino, V.P. Wrenn, B. Cicek, N.V. Urbain, and J. Manem. 1995. Effectiveness of the Membrane Bioreactor in the Biodegradation of High
Molecular-weight Compounds. Wat Sci Tech. 34: 197-203.

[7] Sridang, P., T. Chubuathong, and S. Petchthong. 2007. Filterability Study of MLSS and Membrane Fouling on Plane Organic Membrane in Frontal Filtration. Thai Environmental Engineering Journal. 21(2): 67-77.

[8] Sridang, P.C., P. Pottier, C. Wisniewski, and A. Grasmick. 2008. Performance and Microbial Surveying in Submerged Membrane Bioreactor for Seafood Processing Wastewater Treatment. Journal of Mem Sci. 317: 43-49.

[9] Sridang, P.C., J. Lobos, A. Pottier, C. Wisniewski, and A. Grasmick. 2008. Biomass Adaptation to Complex Substrate Degradation in Membrane Bioreactors: Appropriated Operating Conditions. Wate Science Technology. 57(1): 33-40.

[10] APHA, AWWA and WEF. 1998. Standard Methods for the Examination of Water and Wastewater. $20^{\text {th }}$ ed. Maryland: American Public Health Association.

[11] Xing, C.H., X.H. Wena, Y. Qiana, and E. Tardieub. 2001. Microfiltration Membrane Coupled Bioreactor for Urban Wastewater Reclamation. Desalination. 141: 63-73.

[12] Khor, S.L., D.D. Sun, C.T. Hay, and J.O. Leckie. 2006. Comparison of Submerged Membrane Bioreactor in Different SRT Conditions. M.S. Thesis. Nanyang Technological University.

[13] Chansongglod, K. 2007. Organic Matter and Nitrogen Removal from Seafood Processing Industry Wastewater (Surimi) by Membrane Bioreactor. M.S. Thesis. Prince of Songkla University.

[14] Defrance, L., and M.Y. Jaffrin. 2005. Cornparison between Filtrations at Fixed Transmembrane Pressure and Fixed Permeate Flux: Application to a Membrane Bioreactor used for Wastewater Treatment. Journal of Mem Sci. 152: 203-210. 